\title{
EXPERIMENTAL ANALYSIS OF THE SHEAR BEHAVIOR OF CONCRETE UNDER HIGH CONFINEMENT
}

\author{
R. ABDUL-RAHMAN", P. FORQUIN", J.L. DECOSNE \\ 3SR Lab, Grenoble Alpes University \\ Grenoble, France \\ e-mail: reem.abdulrahman@3sr-grenoble.fr, pascal.forquin@3sr-grenoble.fr
}

Key words: Punching-through shear test, Confinement, shear loading.

\begin{abstract}
Geomaterials undergo severe tensile and shear damage when subjected to extreme loading conditions such as impact or blast loadings. In order to reproduce high confinement levels with large shear deformations, a new testing device was developed. A cylindrical sample with two cylindrical notches is first subjected to hydrostatic pressure up to $100 \mathrm{MPa}$ using a very highcapacity triaxial press. Then, this pressure being kept constant, an axial displacement is applied in order to generate a shear deformation in the ligament. First, numerical simulations were conducted to optimize notches and sample dimensions. Computations have shown that it is necessary to introduce rings around the unconfined region of the specimen to avoid its compressive failure. Then, preliminary experiments were conducted and it was observed that mode II cracks propagated inside the predetermined zone of the concrete specimen and that shear stress increases with the increase of confinement pressure.
\end{abstract}

\section{INTRODUCTION}

During blasting, penetration of projectiles into concrete and many other severe loadings, various localized effects including cratering, tunneling and spalling are generated inside the concrete [1]. Under such conditions, shear deformation and high confining pressures can be observed. Extensive studies were carried out to study the behavior of concrete under high confinement [2,3] using a high-capacity hydraulic triaxial press called GIGA. But fracture of this material under mode II conditions remains largely unstudied. Few tests have been developed for determining shear behavior of concrete under confined or unconfined conditions. A recent experimental technique was developed to study the shear fracturing in mode II. Luong [4] used cylindrical samples with centered coinciding circular notches drilled on top and bottom surfaces leaving a cylindrical shear ligament. More recently, Bakers et al. [5] conducted laboratory Punch-through shear (PTS) tests on three different types of rock (granite, marble and limestone) subjected to up to $70 \mathrm{MPa}$ of confining pressure to measure Mode II fracture toughness. The specimen was first subjected to a hydrostatic pressure and then an axial load was applied to punch through the central portion of the core. They concluded that fracture toughness increases linearly with confining pressure and reaches asymptotically a constant value at confining pressures higher than 20-35 MPa. Montenegro et al. [6] observed an increase of dissipation of energy associated to mode II fracture in confined conditions and concluded that shear strength increases and dilatancy effect decreases with higher confinement. Forquin [7] conducted experiments on dry and wet concrete samples 
with passive confinement cells and with radial notches to avoid self-confinement of the sample peripheral part. The author observed higher strength in dry samples compared to wet samples and higher shear strength when using steel passive confinement ring rather than aluminium one. Forquin [8] also studied the behavior of concrete under high strain rates and concluded that both sets of concrete (dry and wet) have very small sensitivity to strain rates up to $100 / \mathrm{s}$ in mode II fracturing. In the existing literature, most of the available experimental tests deal with moderate confining pressure.

In the present work, PTS tests have been conducted with a high-capacity triaxial press. The first part of this paper will present some of the numerical simulations used to optimize sample geometry. Second part will describe the experimental tools used to conduct the PTS tests and finally some preliminary experimental results will be shown.

\section{NUMERICAL SIMULATIONS}

In order to determine the optimal sample geometry, numerical simulations have been conducted with the finite element code Abaqus/explicit. The sample diameter was taken equal to $70 \mathrm{~mm}$ as required for the Giga press and the notches width equal to 3.5 and $4 \mathrm{~mm}$ imposed by the drilling tools. Samples with different geometries with respect to the sample length and the notch depth and diameter have been considered to study the influence of each parameter on the response of the sample.

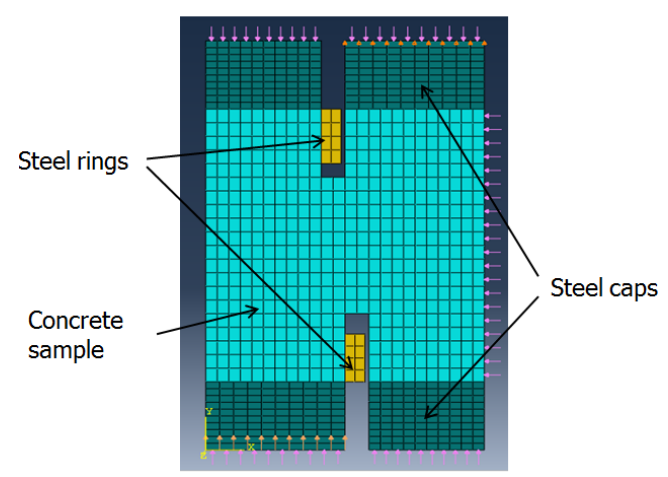

Figure 1: Sample geometry and loading in finite element model
The Drucker-Prager model was used and 2D axisymmetric calculations were performed. The material constants with regards to the constitutive model used are $\sigma_{\mathrm{c}}=45 \mathrm{MPa}$, $\beta=45^{\circ}$ and $\Psi=10^{\circ}$. In the first phase, the sample is subjected to hydrostatic pressure than a velocity is applied on the central part of the specimen to produce the shear displacement.

\subsection{Influence of rings}

Because of the notches drilled into the specimen, the top and bottom inner parts remain unconfined in the radial direction during the test. The axial stress applied on this zone being larger than the compressive strength of concrete, this zone could be damaged under compression before reaching any shear deformation. Consequently, two small steel rings were designed to prevent the radial deformation of the unconfined notch region. Figure 2 shows the difference in plastic strain in the sample without and with the two rings under a confining pressure of $100 \mathrm{MPa}$.
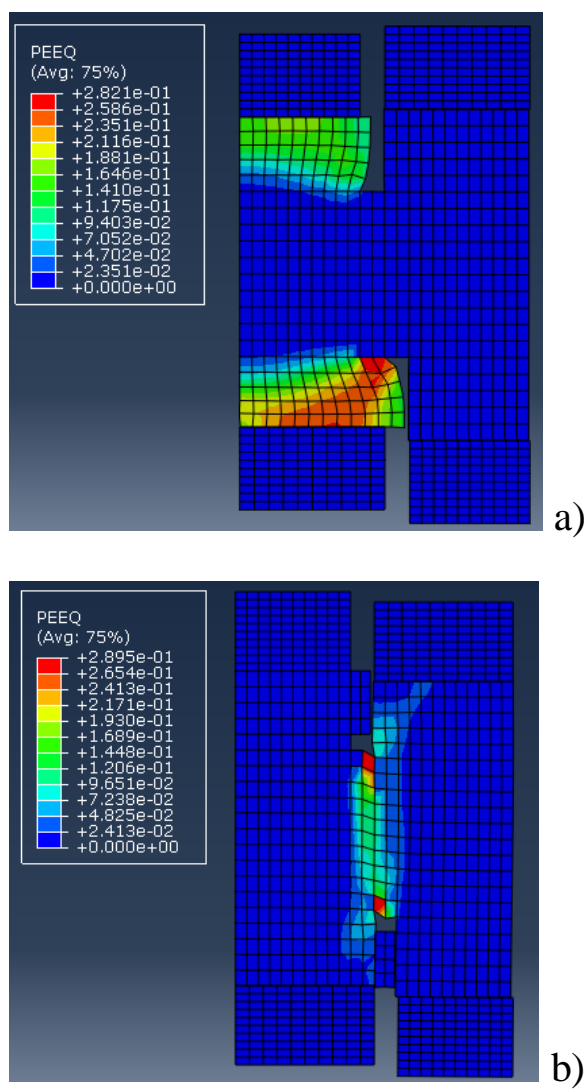

Figure 2: Equivalent plastic strain after $1.3 \mathrm{~mm}$ of displacement a) without and b) with rings 


\subsection{Influence of notch diameter}

The notch diameter was varied between 20 and $45 \mathrm{~mm}$, all the other dimensions being kept constant. The average radial stresses in the ligament under a confining pressure of $100 \mathrm{MPa}$ and its theoretical value are shown in Figure 3 . The theoretical value is calculated by equation (1) assuming that no peripheral confinement is present in the sample.

$$
\sigma_{r r \text { (theoretical })} \times S_{\text {lig }}=P \times S_{\text {ext }}
$$

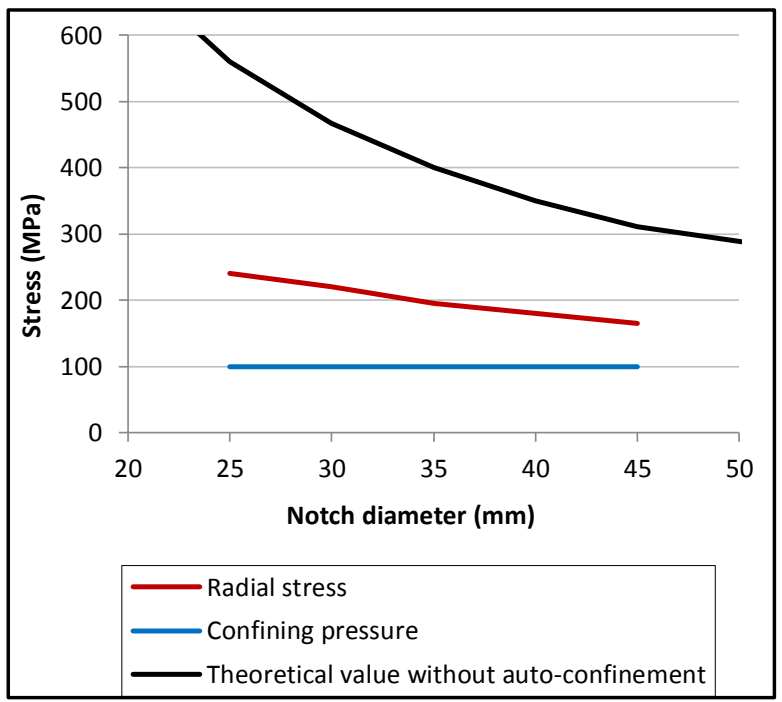

Figure 3: Average true and theoretical radial stresses for different notch diameters. (Numerical simulations)

The true radial stress in the ligament obtained from simulations (red color) decreases for higher notch diameter and the ratio between the theoretical and the real value is smaller. For this reason, the configurations with small notch diameters were not considered. For a large notch diameter (larger than $40 \mathrm{~mm}$ ), a notable bending deformation of the peripheral part was observed due to the reduction of the peripheral thickness. Finally, the $35 \mathrm{~mm}$ diameter was chosen as a compromise between both cases.

\subsection{Influence of ligament length}

To study the influence of the ligament length, the sample length was fixed to $40 \mathrm{~mm}$ and the lower notch length to $10 \mathrm{~mm}$. Figure 4 shows the axial force applied in three different configurations: for upper notch diameter of 10 , 15 and 20 corresponding to a shear length of
20, 15 and $10 \mathrm{~mm}$ respectively, under a confining pressure of $100 \mathrm{MPa}$.

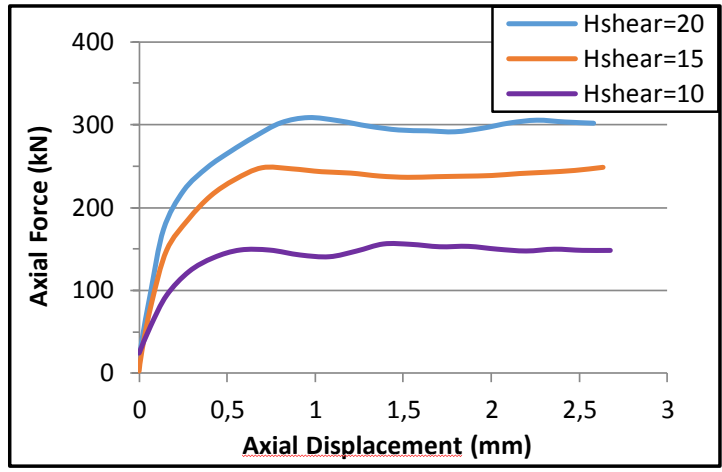

Figure 4: Axial force applied on the central part of the specimen vs axial displacement for different notches lengths. (Numerical simulations)

It is obvious that for higher ligament length, higher force is obtained. And by comparing the shear stress inside the ligament for the three configurations, same value of stresses was observed. The sample with $20 \mathrm{~cm}$ ligament length was chosen to improve the quality of force measurement.

\subsection{Specimen geometry}

The final specimen geometry is a cylindrical sample $70 \mathrm{~mm}$ in diameter and $40 \mathrm{~mm}$ in height. Two cylindrical notches are drilled in the end surfaces such as the inner diameter of lower notch and the outer diameter of upper notch coincide in a way that a straight cylindrical fracture surface is obtained $\left(d_{\text {notch }}=35 \mathrm{~mm}\right)$. The heights of the notches are set to $10 \mathrm{~mm}$ leaving $20 \mathrm{~mm}$ for the ligament length. Regarding the rings, the top has an inner diameter of $28 \mathrm{~mm}$, a thickness of 2.5 $\mathrm{mm}$ and a height of $8 \mathrm{~mm}$, whereas the bottom has an inner diameter of $35 \mathrm{~mm}$, a thickness of $3.5 \mathrm{~mm}$ and a height of $6 \mathrm{~mm}$. The configuration of the concrete tested is presented in the Figure 5.

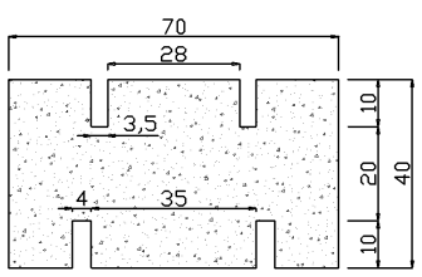

Figure 5: Final configuration tested. 


\section{TESTING PROCEDURE}

\subsection{Experimental device}

A large-capacity triaxial press GIGA was used in the experimental part of the study. Its original design was aimed at applying confinement pressure as large as $0.85 \mathrm{GPa}$ and axial stresses up to $2.35 \mathrm{GPa}$ to cylindrical concrete specimens ( $D=70 \mathrm{~mm}, \mathrm{~L}=140 \mathrm{~mm}$ ).

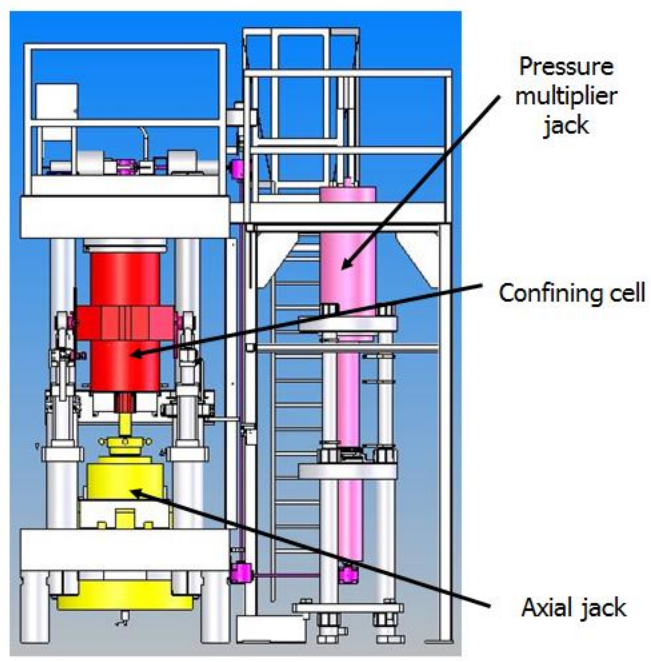

Figure 6: General view of the Giga press

In the already described test configuration, the diameter of the specimen is $70 \mathrm{~mm}$ and the length was taken equal to $40 \mathrm{~mm}$. A loading plate was added to apply a constant displacement for the central part of the specimen. A picture of the press and a section of the loading apparatus designed are shown in Figure 6 and Figure 7 respectively.

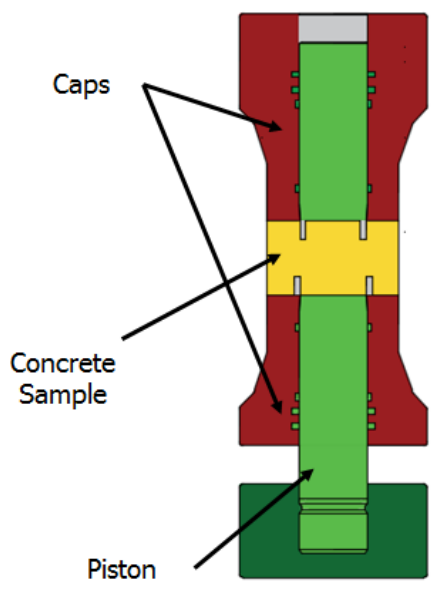

Figure 7: Loading system recently designed
The test begins with a hydrostatic phase, during which confining pressure increases at a rate of $1.67 \mathrm{MPa} / \mathrm{s}$ until reaching the desired pressure. The confining pressure is applied on every surfaces of the sample through the membranes and through the two caps. The deviatoric phase is then conducted, at constant confining pressure, by imposing a constant displacement rate of $20 \mu \mathrm{m} / \mathrm{s}$ for the axial jack.

\subsection{Instrumentation and measurements}

The press is equipped with several sensors that serve to supervise the tests and provide information on the state of the sample during loading. An axial force sensor and pressure sensor positioned inside the confining cell give the stress state on the specimen. Displacement measurements of the central part are performed by using an LVDT (linear variable differential transformer) axial sensor, along with one circumferential gauge. The gauges used for this study are EP-08-10CBE-12 type from Vishay Micro-measurements Company. The steel rings were glued to the sample prior to each test. The glue used is a bi-component resin named Chrysor®. This step was carrefully carried out to avoid any gap between concrete and steel that could otherwise lead to non desirable damage due to non-effective confinement.

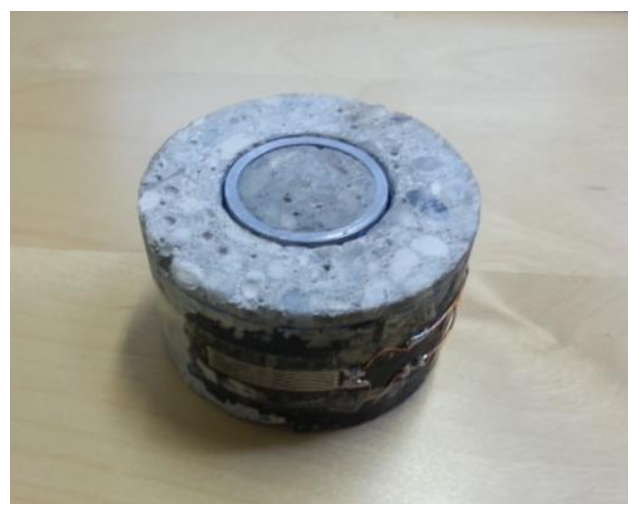

Figure 8: Concrete sample equipped with a ring

\subsection{Material properties}

The concrete composition and its mechanical properties are provided in Table 1. It has a mean strength of $30 \mathrm{MPa}$ in compression after 28 days and a $7 \mathrm{~cm}$ slump. 
Table 1: Composition and mechanical properties of R30A7

\begin{tabular}{cc}
\hline Concrete mix proportions & $\mathrm{Kg} / \mathrm{m}^{3}$ \\
\hline Water & 169 \\
\hline Sand D (diameter) $\max 1.8 \mathrm{~mm}$ & 838 \\
\hline Aggregate D 0.5 to 8mm & 1007 \\
\hline Cement CEM I 52.5N & 263 \\
\hline \multicolumn{2}{c}{ Mechanical properties } \\
\hline $\begin{array}{c}\text { Average Compression strength } \\
\text { after 28 days (MPa) }\end{array}$ & 28.6 \\
\hline Average slump (cm) & 6.9 \\
\hline Porosity accessible to water (\%) & 12 \\
\hline W/C ratio & 0.64 \\
\hline
\end{tabular}

\section{EXPERIMENTAL RESULTS}

In order to verify the testing technique performance, two preliminary tests have been carried out at two different levels of confining pressure (50 and $100 \mathrm{MPa})$. It was noticed after the tests that the central part of concrete specimens was not damaged under compression on one hand and that the rings diameter remained constant on the other hand. These observations confirmed that the rings stayed in the elastic deformation regime and allowed the confinement of the central part of the specimen.

\subsection{Shear Strength}

The shear stress versus the vertical displacement is reported in Figure 9. A ductile behavior is noted after the peak stress. According to Figure 9, the maximum shear stress reaches about $78 \mathrm{MPa}$ with $50 \mathrm{MPa}$ confinement and $94 \mathrm{MPa}$ for $100 \mathrm{Mpa}$ of confinement. This difference confirms the pressure sensitivity of concrete under shear loading.

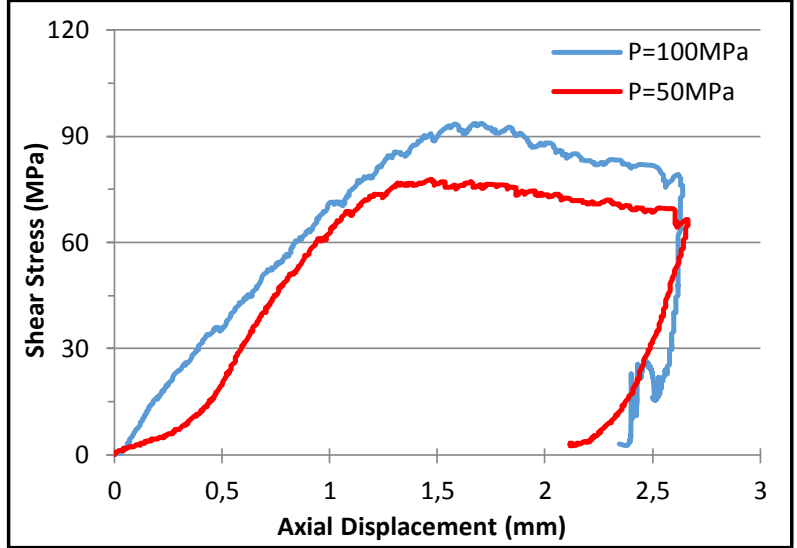

Figure 9: Results of static tests under 50 and $100 \mathrm{MPa}$ of confining pressure

\subsection{Post-mortem sample feature}

Figure 10 shows a concrete specimen tested under a confining pressure equal to $50 \mathrm{MPa}$ in which we can see one tensile radial crack created in the peripheral part. The specimen tested under a $100 \mathrm{MPa}$ of confinement is shown in figure 11. No radial cracks were observed in the specimen.
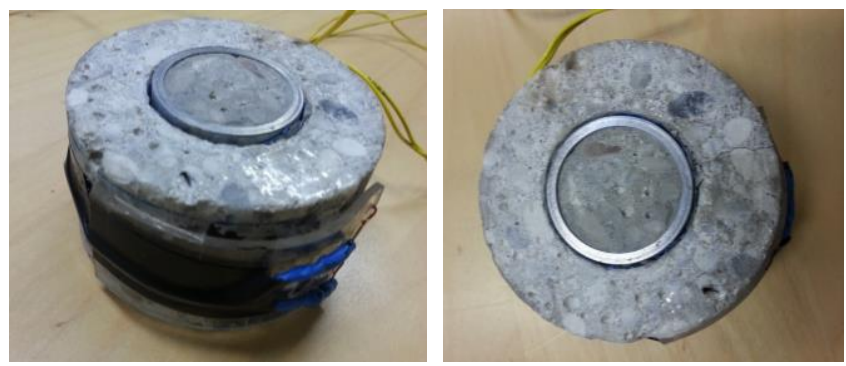

Figure 10: Concrete specimen subjected to a confining pressure of $50 \mathrm{MPa}$.
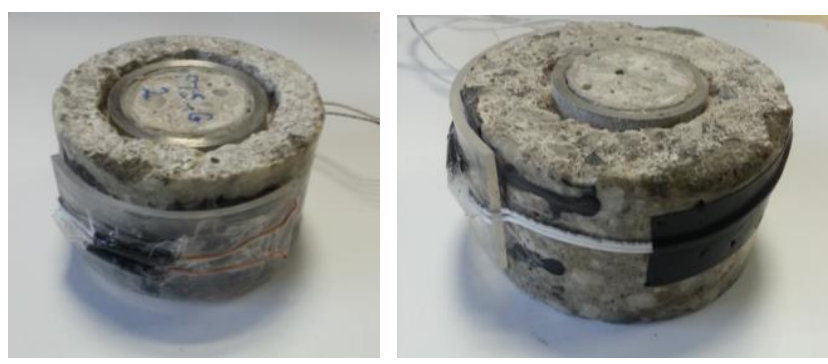

Figure 11: Concrete specimen subjected to a confining pressure of $100 \mathrm{MPa}$.

\section{CONCLUSIONS}

A new experimental technique has been developed to study the shear behavior of 
concrete under high confinement. Giga Press has been used to apply confining pressure up to $100 \mathrm{MPa}$ and two steel rings were glued to the central part of the specimen to prevent it to be damaged under compression. Preliminary tests have been conducted with two different levels of confining pressure and the results showed the increase of shear stress with confinement and the existence of mode II fracture inside the concrete.

\section{REFERENCES}

[1] Zukas, J.A. 1992. Penetration and perforation of solids, Impact Dynamics. Krieger Publishing Co.

[2] Gabet, T., Malecot,Y. And Daudeville, L. 2008. Triaxial behavior of concrete under high stresses: Influence of the loading path on compaction and limit states. Cement and concrete Research. 38(3): 403-412

[3] $\mathrm{Vu}, \mathrm{X}$. , Malecot,Y., Daudeville, L. and Buzaud, E. 2009. Experimental analysis of concrete behavior under high confinement: Effect of the saturation ratio. International Journal of solids and structures. 46(5): 1105-1120

[4] Luong, M.P. 1992. Fracture testing of concrete and rock materials. Nuclear Engineering and Design. 133: 83-95.

[5] Backers, T., Stephansson, O. and Rybacki, E. 2002. Rock fracture toughness testing in mode II- Punch-through shear test, International journal of Rock mechanics and Mining Sciences 39:755-769.

[6] Montenegro, O., Sfer, D., Lopez, CM. and Carol, I. 2013. Experimental tests and numerical modeling to indentify the asymptotic shear-compression mode IIa of concrete fracture. In J.G.M Van Mier, et al (Eds) Proc. of the VIII International Conference on Fracture Mechanics of Concrete and Concrete Structures.(Framcos 8); pp. 271-277.

[7] Forquin, P. 2011. Influence of Free Water and Strain-Rate on the Shear Behavior of Concrete, Applied Mechanics and Materials 82:148-153.
[8] Forquin, P., Sallier, L. 2011. Influence of strain-rate and confining pressure on the shear strength of Concrete, Dynamic Behavior of Materials 1:29-35 